\title{
SISTEM PENCARIAN LOKASI DAN RUTE TERDEKAT MENGGUNAKAN METODE HAVERSINE FORMULA PADA APLIKASI DONATUR PAKAIAN BERBASIS ANDROID
}

\author{
Silvia Kartika ${ }^{1}$, Suendri ${ }^{2}$, dan Raissa Amanda Putri ${ }^{3}$ \\ ${ }^{123}$ Universitas Islam Negeri Sumatera Utara, Medan, Indonesia \\ e-mail: ${ }^{1}$ silviakartika99@gmail.com, ${ }^{2}$ suendri@uinsu.ac.id, ${ }^{3}$ raissa.ap@uinsu.ac.id
}

\begin{abstract}
Donations are not only in nominal form but also can be form of used goods such as clothes. Currently, there is no app to accommodate donors to donate clothes or fundraisers who are looking for clothes. The process of raising donations is also still fairly manual because you have to distribute brochures, communicate via messages, then determine the place and time of collection. Constraints faced were the lack of information related to fundraising, the timing was not suitable, and the distance was long. By implementing the haversine formula method so that this system can determine the distance and the closest route from the location of the raiser to the location of the donor. This system is based on android, built using openstreetmap, kodular, and MySQL database. The goals of this android app is to be a forum as a link between donations and fundraisers and to help make the donation-raising process more effective and efficient.
\end{abstract}

Keywords: Donation, Android Application, Haversine Formula

\section{PENDAHULUAN}

Di kala ini, perkembangan teknologi semakin pesat dapat kita rasakan. Seiring dengan perkembangan itu pula, banyak perubahan yang terjadi dalam kegiatan sehari-hari. Banyak pekerjaan menjadi lebih tersistem, lebih mudah, dan lebih efektif karena dibantu oleh teknologi. Akibat positif dari kemajuan teknologi dan informasi di kala ini juga yaitu segala proses yang berhubungan dengan pengolahan data dapat dengan tepat dikelola secara tersistem, dengan begitu hasil keluaran dari pengolahan tersebut menjadi lebih terstruktur, akurat dan lebih menghemat waktu serta mengurangi biaya (Putri, 2018). Manfaat lain yang dapat dirasakan dari kemajuan teknologi ini membantu di setiap bidang pekerjaan, salah satunya di bidang sosial yaitu dalam hal berdonasi. Melakukan aktivitas berdonasi termasuk satu dari kegiatan penting yang dapat dilakukan dalam bersosial. Donasi tidak selalu berbentuk nominal tetapi juga dapat berupa barang seperti pakaian bekas layak pakai.

Donasi berasal dari bahasa inggris yaitu donation. Donasi adalah berupa pemberian secara sadar dan besifat sukarela tanpa adanya paksaan dan tanpa berharap adanya sebuah balasan. Donasi yang familiar kita ketahui biasanya bersifat fisik baik berupa barang bekas layak pakai, pakaian, mainan, makanan, minuman, buku dan lain sebagainya. Setiap individu, kelompok, organisasi, dan lainnya dapat melakukan aktivitas donasi tersebut kapanpun dan di manapun (Yuliyanti, 2018). Donasi juga diartikan sebagai suatu kegiatan kemanusiaan atau kegiatan sosial dengan tujuannya yaitu untuk aktivitas sosial (Amalia, 2017). Mereka yang memberikan donasi baik secara tetap maupun tidak tetap, baik secara individu maupun dalam satuan kelompok, organisasi, atau badan lembaga disebut dengan donatur (Santoso, 2020).

Saat ini proses penggalangan donasi di Kota Medan masih dilakukan secara manual, dengan membuat dan menyebarkan flyer atau brosur, lalu berkomunikasi melalui sosial media untuk menentukan tempat dan waktu pengambilan donasi. Hal tersebut memiliki beberapa kendala diantaranya komunikasi antara pihak penggalang donasi dan donatur kadang kala tidak mendapatkan keputusan, jarak, waktu, serta tempat pengambilan lokasi yang tidak cocok, dan sebagainya. Sistem ini akan 
mengimplementasikan metode haversine formula yaitu rumus yang didasari dari bentuk bumi yang tidak elips melainkan bulat (Setiawan, 2020). Metode ini untuk memperhitungkan besarnya jarak yang ada di antara dua buah titik yang diambil dari titik latitude (lintang) dan longitude (bujur). Persamaan haversine formula dapat dilihat di bawah ini:

$\Delta l a t=$ lat $2-$ lat 1

$\Delta$ long $=\operatorname{long} 2-\operatorname{long} 1$

$a$

$=\sin ^{2}(\Delta l a t / 2)$

$+\cos ($ lat 1$) \cdot \cos ($ lat 2$) \cdot \sin ^{2}(\Delta$ long $/ 2)$

$c=2 \cdot \operatorname{atan} 2(\sqrt{a}, \sqrt{1-a})$

$d=R . c$

Keterangan:

$\mathrm{R}=$ jari-jari bumi sebesar $6371(\mathrm{~km})$.

$\Delta$ lat $=$ besaran perubahan latitude.

$\Delta$ long $=$ besaran perubahan longitude.

$\mathrm{c} \quad=$ kalkulasi perpotongan sumbu.

$\mathrm{d}=$ jarak $(\mathrm{km})$.

1 derajat $=0.0174532925$ radian. (Putra, Sujiani and Safriadi, 2015)

Aplikasi yang akan dibangun berbasis aplikasi mobile yaitu platform seluler yang dirancang khusus, yang menyajikan proses interaksi interface yang menarik, unik, saling berinteraksi dengan sumber daya web, mempunyai kemampuan untuk melakukan pemrosesan secara internal, serta juga tersedia kemampuan dalam hal penyimpanan secara konsisten di dalam suatu platform (Samsudin, Irawan and Harahap, 2019). Dalam hal ini penulis menggunakan aplikasi mobile Android.

Pada penelitian ini menggunakan pemodelan sistem dengan menggunakan UML. UML (Unified Modelling Language) adalah bahasa pemodelan software untuk memberikan jabaran rinci dan menganalisa kebutuhan aplikasi atau sistem dengan konsep object-oriented programming (Suendri, 2019). UML, yaitu usecase diagram, activity diagram, sequence diagram, class diagram dan beberapa diagram lainnya (Samsudin, Irawan and Harahap, 2019). Dalam penelitian ini penulis hanya menggunakan 4 (empat) desain UML. Diagram usecase bertujuan untuk mengetahui di dalam suatu sistem apa-apa saja fungsi yang akan dilakukan serta siapa-siapa saja yang memiliki hal untuk mengakses fungsi itu (Irawan and Simargolang, 2018). Sequence diagram menggambarkan aktivitas siapa-siapa saja yang terlibat dalam sebuah sistem yang didasari oleh urutan waktu. Sedangkan class diagram untuk menggambarkan proses interaksi diantara setiap class (Kurniawan, Suendri and Triase, 2019).

Terdapat penelitian sebelumnya yang dilakukan oleh Dyna Marisa Khairina, Febrian Wicaksana Ramadhinata, dan Heliza Rahmania Hatta dalam jurnal "Pencarian Lokasi Jalur Nugraha Ekakurir (JNE) Terdekat Menggunakan Haversine Formula (Studi Kasus Kota Samarinda)" yang menghasilkan lokasi Jalur Nugraha Ekakurir (JNE) namun belum menunjukkan rute yang dapat dilalui oleh pengguna (Khairina et al., 2017). Terdapat juga penelitian oleh Septya Maharani, Awang Harsa K, dan Atik Tia Nalarwati dalam jurnal "Sistem Informasi Geografi (SIG) Pencarian ATM Bank Kaltim Terdekat dengan Geolocation dan Haversine Formula Berbasis Web" yang menampilkan hasil berupa lokasi ATM Bank Kaltim terdekat namun juga tidak menunjukan rute yang dapat ditempuh oleh pengguna (Maharani et al., 2017).

Berdasarkan uraian di atas, aplikasi bertujuan sebagai wadah yang menghubungkan antara pihak penggalang donasi dan pihak donatur. Aplikasi ini dapat digunakan oleh donatur untuk melakukan donasi pakaian dan donatur dapat menentukan sendiri tempat dan waktu pengambilan donasi pakaian tersebut. Sedangkan penggalang donasi dapat menggunakan aplikasi ini untuk mencari donatur terdekat dalam jangkauan jarak $<=5 \mathrm{Km}$ dari lokasinya. Jangkauan jarak $5 \mathrm{Km}$ dirasa sesuai karena tidak terlalu jauh dari lokasi pengguna, hal ini berdasarkan hasil observasi dan wawancara kepada masyarakat dan organisasi di Kota Medan sebagai penggalang dan donatur pakaian. Pada aplikasi ini juga telah menampilkan rute yang dapat ditempuh oleh pengguna dari lokasi awal menuju lokasi tujuan serta aplikasi ini berbasis Android sehingga dapat dibuka tanpa mengenal waktu kapan dan berada pada saat di mana asal terhubung akses internet. Aplikasi ini diharapkan dapat membantu proses penggalangan donasi agar lebih efisien dan efektif.

\section{METODE PENELITIAN \\ Kerangka Kerja}

Agar penelitian berjalan dengan baik, sistematis, dan terstruktur maka perlu adanya sebuah kerangka berpikir mengenai alur proses pengerjaan secara teratur. Pada kerangka berpikir terdapat beberapa tahapan yaitu: 


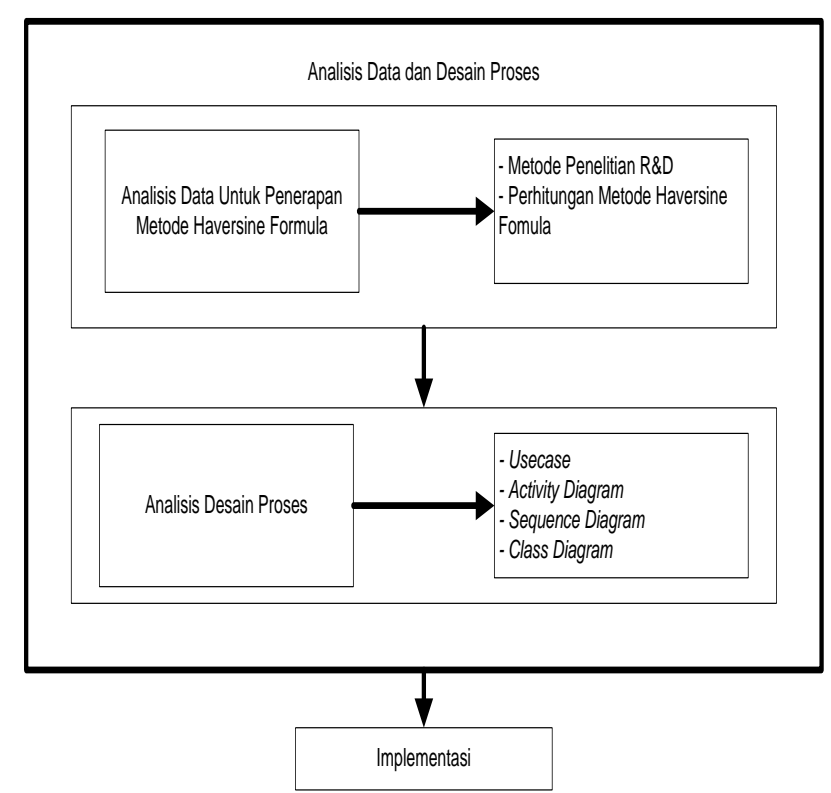

Gambar 1. Kerangka Berpikir

Berikut adalah penjelasan terkait kerangka kerja yang tertera di atas:

1. Analisis data dan desain proses, yaitu tahapan ini untuk menganalisis masalah yang dihadapi dan juga menganalisis tepatnya penerapan penyelesaian seperti apa yang dapat membantu memecahkan masalah tersebut. Pada tahapan analisis data, terdapat tahapan metode penelitian R\&D (Research and Developmnet) serta perhitungan metode haversine formula yang mana metode ini akan diterapkan ke dalam aplikasi untuk membantu penyelesaian masalah. Untuk tahapan analisis desain proses, yakni menggunakan UML (Unified Modelling Language), yang terdiri dari ucecase, activity diagram, sequence diagram, dan class diagram.

2. Implementasi, pada tahapan ini yaitu mengimplementasikan proses pada tahapan sebelumnya dan diimplementasikan dengan bantuan komponenkomponen berupa perangkat keras (Laptop dan Smartphone) dan perangkat lunak (Kodular, OpenStreetMap, MySQL).

\section{Metode R\&D (Research and Development)}

Metode ini penulis gunakan dalam proses pengumpulan data.

1. Wawancara, yaitu dengan bertanya langsung kepada pihak terkait yaitu dalam penelitian ini adalah masyarakat dan organisasi di Kota Medan terkait proses pendonasian pakaian dan proses penggalangan donasi pakaian yang berjalan saat ini.
2. Observasi, yaitu dengan terjun langsung melakukan pengamatan terkait proses pendonasian pakaian dan proses penggalangan donasi.

3. Studi Pustaka, yaitu dengan membaca dan memahami buku, jurnal, serta penelitian yang pernah dilakukan sebelumnya terkait dengan penelitian yang penulis angkat saat ini.

\section{HASIL DAN PEMBAHASAN}

Paparan pada kerangka berpikir yang telah dirancang pada tahap sebelumnya akan diimplementasikan pada bagian hasil dan pembahasan berikut ini.

\section{Data Sampel Lokasi Donatur}

Data-data yang diperoleh ketika melakukan proses pengumpulan data, sehingga menghasilkan data-data berupa data alamat lokasi doantur, titik latitude, dan titik longitude.

Tabel 1. Data Lokasi Donatur

\begin{tabular}{|c|c|c|c|}
\hline No & Alamat & Latitude & Longitude \\
\hline 1 & $\begin{array}{l}\text { Gg. Sani Buntu, } \\
\text { Sidorame Bar. I, } \\
\text { Kec. Medan } \\
\text { Perjuangan. }\end{array}$ & 3.603727 & 98.68380 \\
\hline 2 & $\begin{array}{l}\text { Jl. Sutomo, Gaharu, } \\
\text { Kec. Medan Timur. }\end{array}$ & $\begin{array}{c}3.60189090203 \\
973\end{array}$ & $\begin{array}{c}98.6801776 \\
183183\end{array}$ \\
\hline 3 & $\begin{array}{l}\text { Gang pinang No. } \\
\text { 12, jalan H.M. } \\
\text { Yamin, Medan } \\
\text { perjuangan. }\end{array}$ & $\begin{array}{c}3.59802845117 \\
787\end{array}$ & $\begin{array}{c}98.6972059 \\
253067\end{array}$ \\
\hline 4 & $\begin{array}{l}\text { Jl. Durung, gang } \\
\text { buntu no 52B, } \\
\text { Medan Tembung. }\end{array}$ & $\begin{array}{c}3.60956502416 \\
119\end{array}$ & $\begin{array}{c}98.6970254 \\
554895\end{array}$ \\
\hline 5 & $\begin{array}{l}\text { Jl. seser, No.24 } \\
\text { Sidorejo Hilir. }\end{array}$ & $\begin{array}{c}3.61233335532 \\
105\end{array}$ & $\begin{array}{c}98.6967488 \\
677973\end{array}$ \\
\hline
\end{tabular}

\section{Perhitungan Metode Haversine Formula}

Langkah pertama adalah dengan menentukan titik awal (latitude1 dan longitude1) yaitu sebagai lokasi penggalang donasi dan titik tujuan (latitude2 dan longitude2) yaitu sebagai lokasi donatur. Titik awal berada di Jl. H.M. Said No.110, Sidorame Bar.I, Kec.Medan perjuangan, dengan titik koordinat (3.60541946909029, 98.6824599580436). Untuk sampel titik tujuan atau lokasi donatur di Kota Medan, tertera pada Tabel 1 di atas.

Contoh perhitungan haversine formula untuk salah satu sampel lokasi sehingga menghasilkan hasil akhir berupa jarak dalam satuan kilometer seperti yang tertera pada Tabel 2 . 


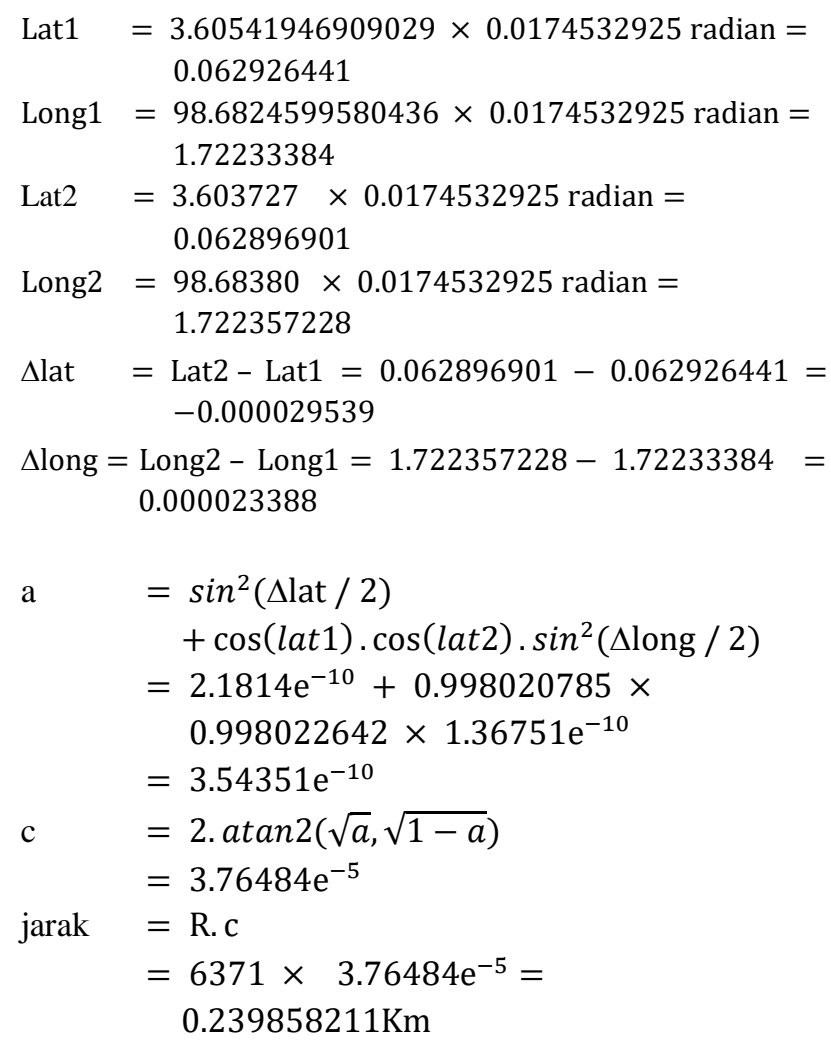

\section{Usecase Diagram}

Usecase diagram menggambarkan kegiatan aktor dan kaitannya. Usecase diagram tertera pada gambar berikut ini.

Tabel 2. Hasil Jarak Perhitungan Menggunakan Haversine Formula

\begin{tabular}{|c|c|}
\hline Alamat & $\begin{array}{c}\text { Hasil Perhitungan } \\
\text { Jarak (Km) }\end{array}$ \\
\hline $\begin{array}{c}\text { Gg. Sani Buntu, Sidorame Bar. } \\
\text { I, Kec. Medan Perjuangan. }\end{array}$ & 0.239858211 \\
\hline $\begin{array}{c}\text { Jl. Sutomo, Gaharu, Kec. } \\
\text { Medan Timur. }\end{array}$ & 0.467009172 \\
\hline $\begin{array}{c}\text { Gang Pinang No. 12, Jalan H.M. } \\
\text { Yamin, Medan perjuangan. }\end{array}$ & 1.831217295 \\
\hline $\begin{array}{c}\text { Jl. Durung, Gang Buntu No } \\
\text { 52B, Medan Tembung. }\end{array}$ & 1.680844426 \\
\hline Jl. Seser, No.24 Sidorejo Hilir. & 1.762240733 \\
\hline
\end{tabular}

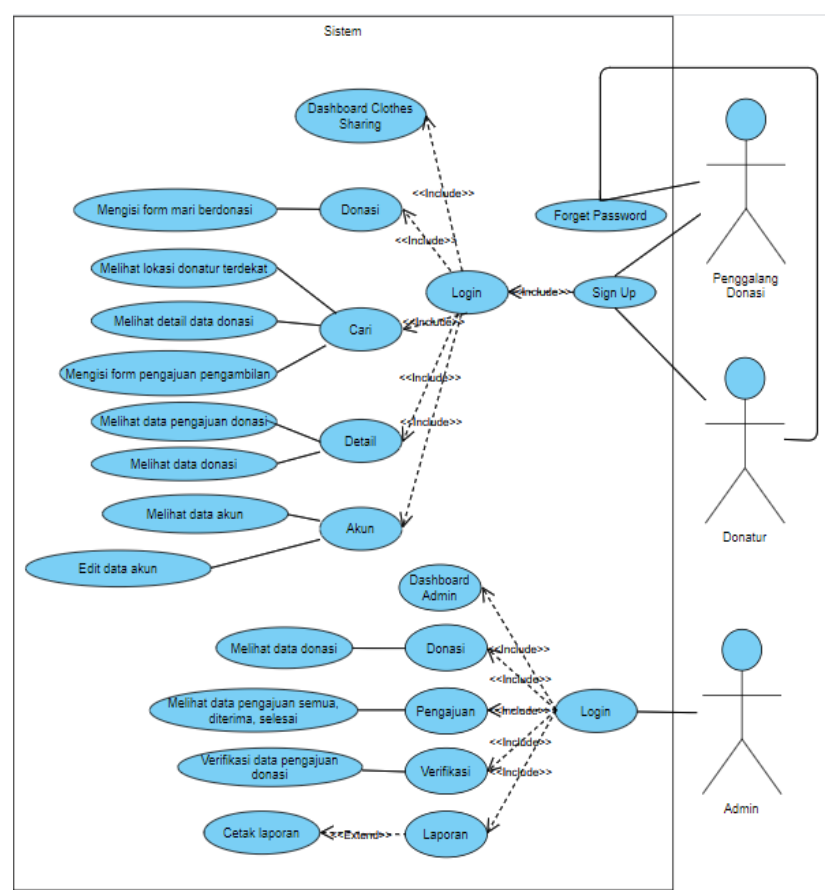

Gambar 2. Usecase Diagram

\section{Activity Diagram}

Berikut di bawah ini merupakan salah satu activity diagram yaitu mengenai proses penggalangan donasi dengan mencari lokasi donatur terdekat.

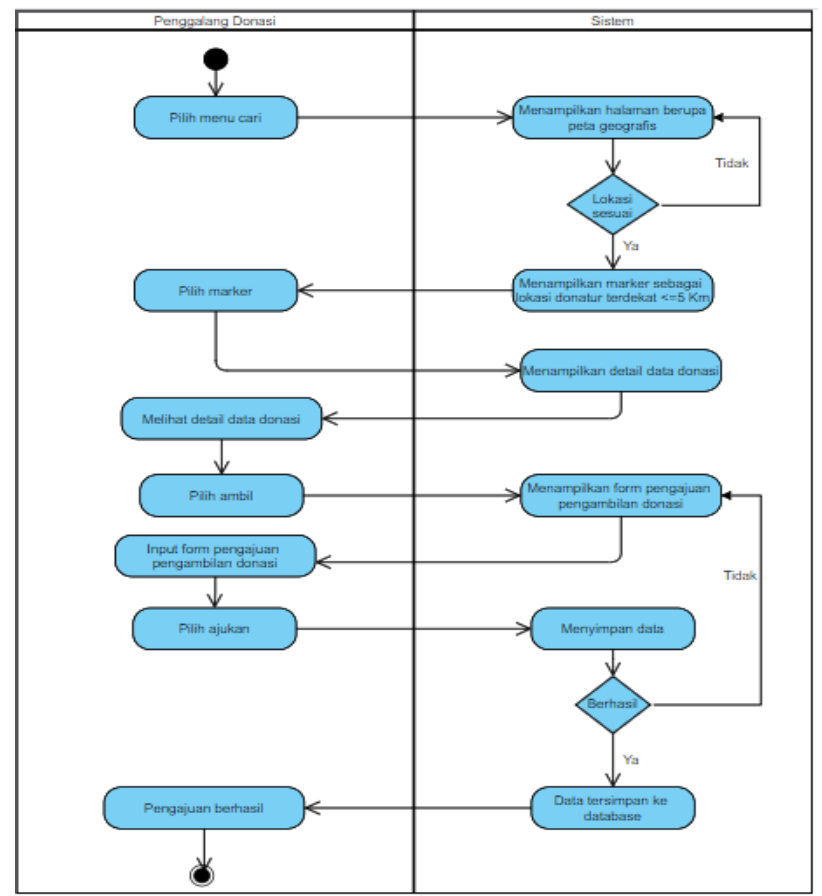

Gambar 3. Activity Diagram

\section{Sequence Diagram}

Berikut di bawah ini adalah salah satu sequence diagram yaitu mengenai proses penggalangan donasi pada aplikasi dengan mencari lokasi donatur terdekat dari lokasi user. 


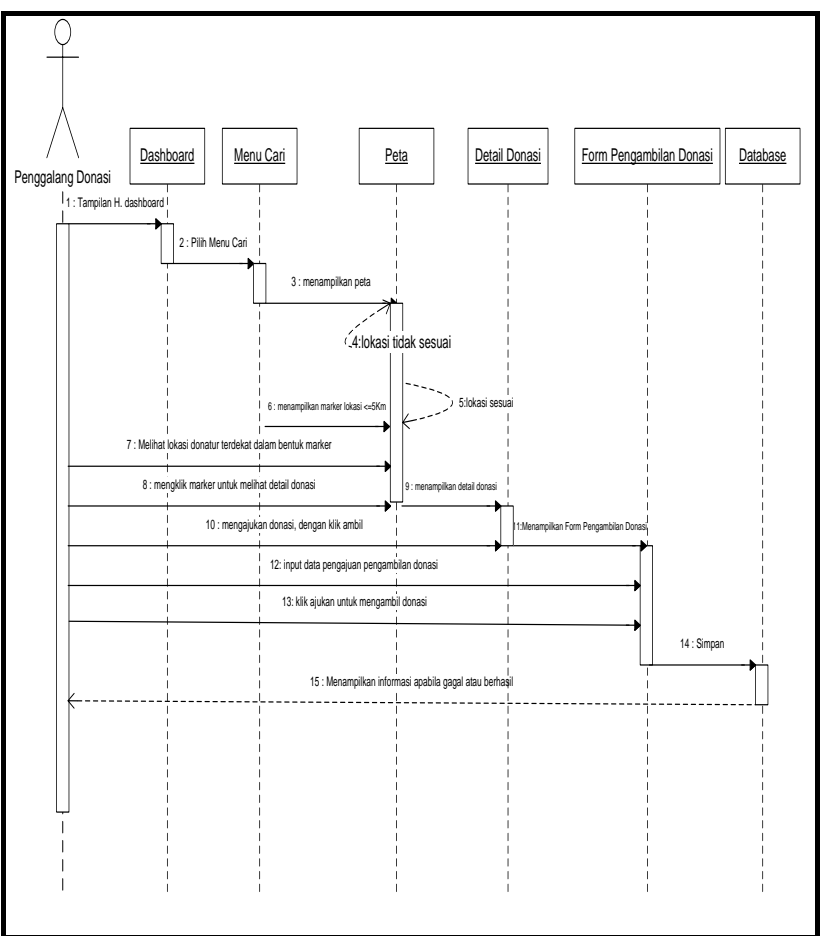

Gambar 4. Sequence Diagram

\section{Class Diagram}

Diagram ini memberikan gambaran terkait interaksi diantara tiap-tiap class yang ada di dalam sistem atau aplikasi yang penulis bangun. Berikut ini di bawah ini adalah class diagram.

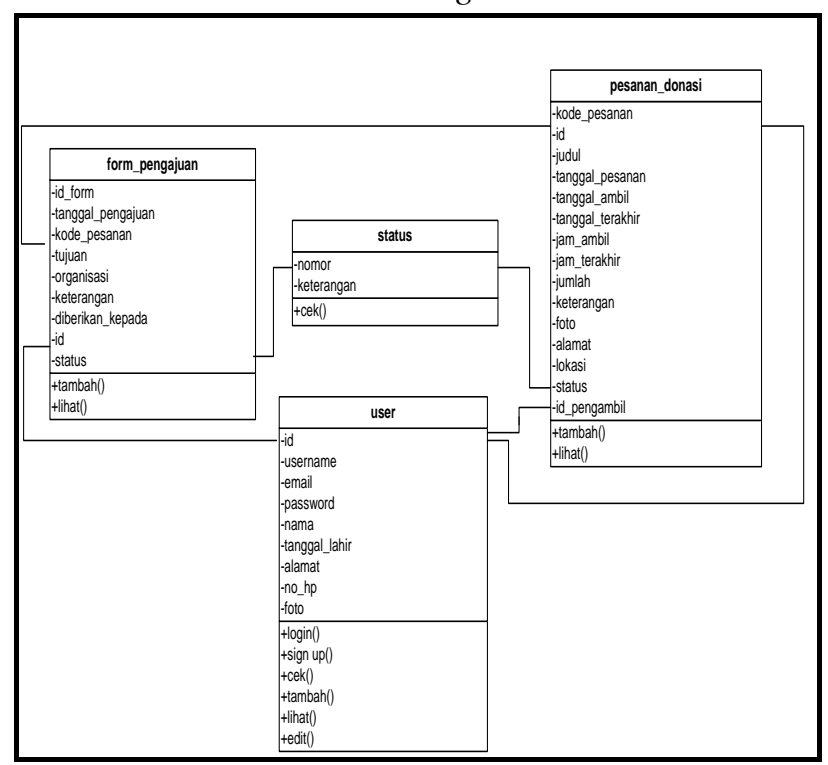

Gambar 5. Class Diagram

\section{Implementasi}

Implementasi berupa gambaran hasil tampilan interface atau tampilan antarmuka pada aplikasi yang selesai penulis bangun. Pada gambar di bawah memperlihatkan tampilan splash screen dan tampilan dashboard aplikasi.
Pada gambar bawah ini akan menunjukkan tampilan lokasi donatur terdekat dengan jangkauan jarak $<=5 \mathrm{Km}$ dalam bentuk marker pada peta geografis. Aplikasi akan membaca lokasi user awal menggunakan GPS dan akan memperlihatkan donaturdonatur terdekat yang ada di lokasi user (penggalang donasi). Perhitungan jarak lokasi donatur terdekat tersebut menggunakan haversine formula. Marker tersebut dapat diklik untuk menampilkan informasi donasi pakaian yang dilakukan oleh donatur.

Pada gambar di bawah ini adalah untuk melihat rute terdekat yang dapat ditempuh oleh penggalang donasi dari lokasinya menuju ke lokasi donatur. Pembuatan rute ini dengan mengimplementasikan metode haversine formula. Pada gambar di bawah ini juga terdapat tampilan implementasi untuk form pengajuan pengambilan donasi pakaian agar pihak donatur mengathui bahwa terdapat penggalang donasi yang membutuhkan donasi tersebut.

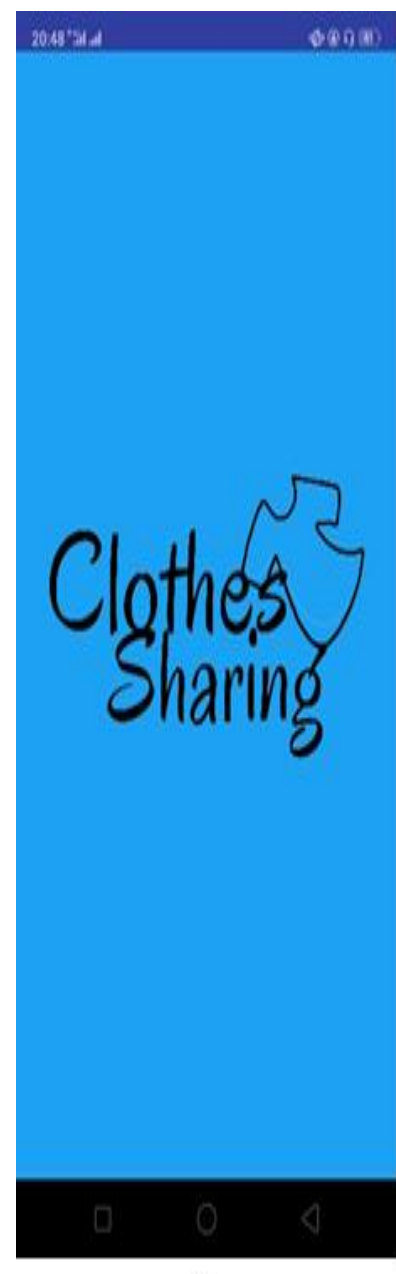

(a)
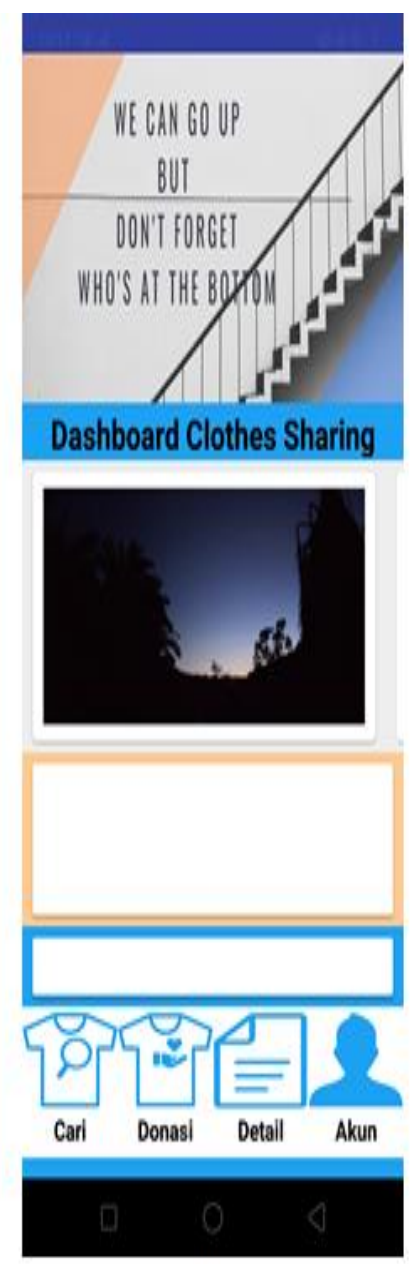

(b)
Gambar 6. (a) Tampilan splach screen aplikasi. (b) Tampilan dashboard aplikasi. 


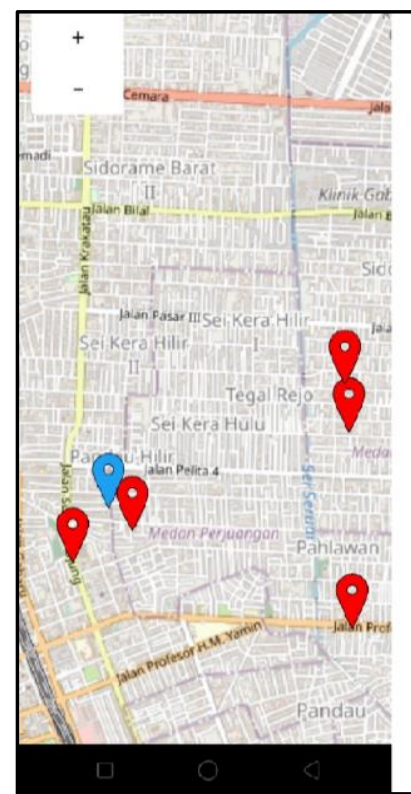

(a)

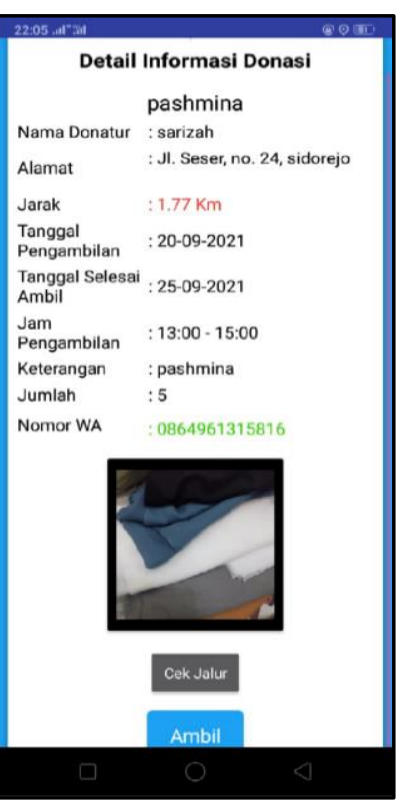

(b)
Gambar 7. (a) Tampilan lokasi donatur terdekat dalam jarak $<=5 \mathrm{Km}$ dari lokasi user berupa marker. (b) Detail informasi donasi

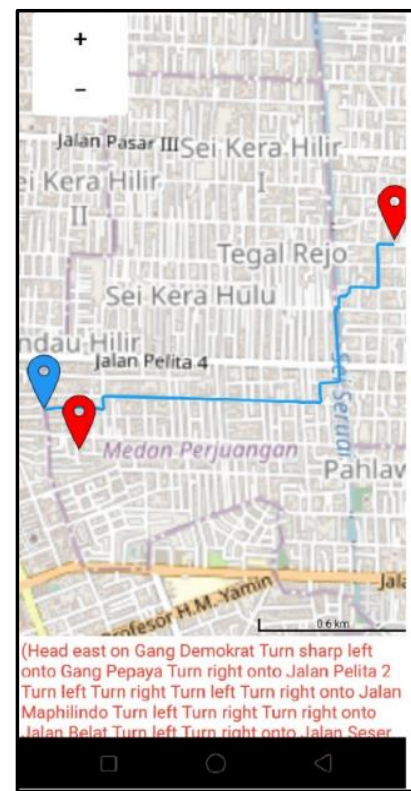

(a)

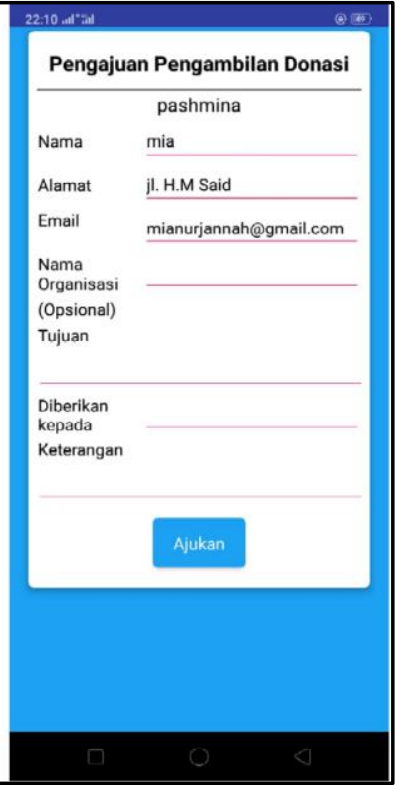

(b)
Gambar 8. (a) Rute terdekat menuju lokasi donatur. (b) Form pengajuan pengambilan donasi

\section{KESIMPULAN DAN SARAN Kesimpulan}

Aplikasi yang dibangun sebagai wadah yang mempertemukan pihak donatur dengan pihak penggalang donasi. Aplikasi ini dapat menampilkan lokasi user saat ini dan dengan mengimplementasikan metode haversine formula pada aplikasi sehingga dapat menampilkan lokasi donatur terdekat yang sedang berdonasi dalam jangkauan jarak $<=5 \mathrm{Km}$ Sistem Pencarian Lokasi dan Rute Terdekat Menggunakan Metode Haversine Formula pada Aplikasi Donatur Pakaian Berbasis Android (Silvia Kartika, Suendri, dan Raissa Amanda Putri) dari posisi penggalang donasi. Aplikasi ini juga dapat memberikan atau menampilkan rute terdekat yang dapat ditempuh dari lokasi awal menuju ke lokasi tujuan. Dengan aplikasi yang berbasis Android sehingga dapat membantu proses penggalangan donasi lebih efektif dan efisien karena dengan aplikasi ini pihak donatur dapat melakukan donasi dengan menetapkan waktu dan tempat sehingga pihak penggalang donasi memilih donatur terdekat yang berada dalam jangkauannya dan mengetahui dengan pasti terkait tempat, jarak, dan waktu pengambilan donasi pakaian, sehingga dengan begitu proses penggalangan donasi pakaian dapat berjalan secara efektif, efisien, dan mudah.

\section{Saran}

Terdapat beberapa saran yang penulis buat untuk penelitian ini, yaitu:

1. Untuk mengakses aplikasi ini agar pengguna dapat menggunakan android versi 4 ke atas karena aplikasi ini dibangun untuk versi android 4 ke atas.

2. Penambahan fitur pemberitahuan untuk mengetahui pengajuan donasi yang masuk dan pemberitahuan jika donasi sudah selesai diambil.

\section{DAFTAR PUSTAKA}

Amalia, H. (2017). Sistem Informasi Pengolahan Dana Donasi, Jurnal Perspektif, 15 (1), Pp. 1-6.

Irawan, M. D. And Simargolang, S. A. (2018). Implementasi E-Arsip Pada Program Studi Teknik Informatika, Jurnal Teknologi Informasi, 2 (1), P. 67.

Khairina, D. M., Ramadhinata, F. W. And Hatta, H. R. (2017). Pencarian Lokasi Jalur Nugraha Ekakurir (JNE) Terdekat Menggunakan Haversine Formula (Studi Kasus Kota Samarinda, Seminar Nasional Inovasi Dan Aplikasi Teknologi Di Industri, Pp. 1-5.

Kurniawan, A., Suendri And Triase (2019). Sistem Informasi Geografis Pemetaan Lokasi Panti Asuhan Di Kota Medan, Jistech (Journal Of Islamic Science And Technology), 3 (2), Pp. 118-126.

Maharani, S. And Nalarwati, A. T. (2017). Sistem Informasi Geografi (Sig) Pencarian Atm Bank Kaltim Terdekat Dengan Geolocation Dan Haversine Formula Berbasis Web, Jurnal Infotel, 9 (1), Pp. 1-8. 
Putra, R. H. D., Sujiani, H. And Safriadi, N. (2015). Penerapan Metode Haversine Formula Pada Sistem Informasi Geografis Pengukuran Luas Tanah, Jurnal Sistem Dan Teknologi Informasi (Justin), 10 (2), Pp. 1262-1270.

Putri, R. A. And Syafina, L. (2018). Pengembangan Sistem Informasi Akuntansi Berbasis Desktop Dengan Metode Stradis, Jurnal Algoritma, 3 (1), Pp. 21-30.

Samsudin, Irawan, M. D. And Harahap, A. H. (2019). Mobile App Education Gangguan Pencernaan Manusia Berbasis Multimedia Menggunakan Adobe Animate Cc, Jurnal Teknologi Informasi, 3 (2), P. 141.

Santoso, M. (2020). Strategi Komunikasi Persuasif Yayasan Karya Salemba Empat Dalam Rekrutment Donatur Beasiswa. Fakultas Ilmu Dakwah Dan Ilmu Komunikasi.

Setiawan, M. H. (2020). Sistem Pencarian Wisata Bima Berbasis Android Menggunakan Metode Haversine Formula. STMIK AKAKOM Yogyakarta.

Suendri, S. (2019). Implementasi Diagram UML (Unified Modelling Language) Pada Perancangan Sistem Informasi Remunerasi Dosen Dengan Database Oracle (Studi Kasus: UIN Sumatera Utara Medan), Algoritma: Jurnal Ilmu Komputer Dan Informatika, 2 (2), p. 1.

Yuliyanti, Y. (2018). Sistem Informasi Pengelolaan Anak Asuh Dan Donasi Di Panti Asuhan Muhammadiyah Sumur Bandung Berbasis Web. Universitas Komputer Indonesia. 